\title{
Experimental Analysis of Composite-to-geopolymer Bonded Structures Using Pull off Tests
}

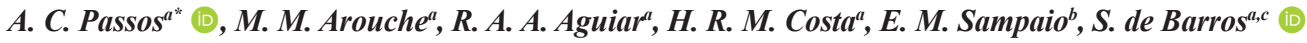 \\ ${ }^{a}$ Centro Federal de Educação Tecnológica Celso Suckow da Fonseca (CEFET/RJ), Av. Maracanã, 229, \\ 20271- 110, Rio de Janeiro, RJ, Brasil. \\ ${ }^{b}$ Universidade do Estado do Rio de Janeiro (UERJ), Instituto Politécnico (IPRJ), Rua do Bonfim, 25, \\ 28625-570, Nova Friburgo, RJ, Brasil. \\ ${ }^{c}$ GeM Institute, UMR 618 CNRS, CESI, Saint-Nazaire, France.
}

Received: September 13, 2021; Revised: November 2, 2021; Accepted: December 3, 2021

\begin{abstract}
Composite materials are employed as an alternative of conventional materials due their attractive properties, such as, environmental resistance and high strength-to-weight ratio. However, a limitation to the application of the composites is the low resistance to high temperatures, due their polymeric matrix. Alternatively, geopolymers are inorganic polymers used mainly instead Ordinary Portland Cement (OPC) in civil engineering. They combine good mechanical properties, corrosion resistance and thermal stability, allowing the use as a thermal barrier. This work regards the combined application of composites and geopolymers through adhesive bonding. The main objective is to evaluate the effect of adhesive type and surface treatment on the adhesion between geopolymer and composite pultruded substrates. Pull off tests were carried out in composite-adhesive-geopolymer sandwich specimens. Different surface treatments were examined: unidirectional abrasion and bidirectional abrasion. Specimens were bonded either with an epoxy or a polyurethane adhesive. The influence of the geopolymer manufacturing process on the performance of the structure was also observed.
\end{abstract}

Keywords: Composite materials, geopolymer, epoxy adhesive, polyurethane adhesive, pull off tests, sandwich structures.

\section{Introduction}

Composite structures are usually manufactured by pultrusion process, which consists in pull continuous fibers in a resin through a mold up to the cure. Carbon, Basalt and glass fibers are applied as reinforcement according to parameters of mechanical properties, cost and availability ${ }^{1-3}$. The use of natural fibers has also been studied ${ }^{4}$. The composite materials present interesting properties that allow their use as an alternative to conventional materials, such as metals. The high strength, light weight, low thermal conductivity and superior environmental resistance $e^{5-8}$ allows the use of composites in structures subjected to aggressive environment with minimum maintenance. However, the polymeric matrix restricts the application of composite materials in sectors where heat resistance is required 9 .

Geopolymers have been applied as an alternative to the Ordinary Portland Cement (OPC) due the comparable performance and lower emission of carbon dioxide $\left(\mathrm{CO}_{2}\right)$ compared with the OPC. More than 13 million tons of $\mathrm{CO}_{2}$ per year are resulted of the OPC manufacturing process, which corresponding of around $7 \%$ of the total emission in the world ${ }^{10-12}$. The geopolymer, also referred as inorganic polymer is resulted from a reaction of solid aluminosilicate and aqueous alkaline hydroxide or silicate solution. The geopolymer chemical and mechanical properties changes according with the composition, what gives flexibility to the production for specific apllications ${ }^{10}$. An important property

*e-mail: acvianapassos@gmail.com of this material is the capacity of maintaining the mechanical properties under high temperatures ${ }^{13,14}$ and fire resistance ${ }^{15}$.

The use of geopolymer plates as a thermal barrier to composites structures requires a efficient union method, ensuring good adhesion and resistance to aggressive environments. Adhesive bonding is one of the most applied method to joint composite profiles due some important vantages such as, lower weight, corrosion resistance, uniform stress distribuition in the bonding area and design flexibility ${ }^{5,16-18}$.

Previously studies revealed better adhesion quality of epoxy and polyurethane adhesives in bonding composite profiles $^{5}$. In the case of bonded pultruded composites, the influence of the adhesive type and surface treatment on the adhesion of bonded is shown to have a significant effect on the joint strength ${ }^{19}$. However, a proper surface treatment must be carefully evaluated in order to ensure high adhesion performance in bonded joints ${ }^{20-23}$. Moreover, delamination failure mode is usually observed in bonded structures with multilayered composite adherend ${ }^{24}$. Complex bonded assemblies, such as bi-material bonded joints, usually require profound experimental evaluation in order to optimize the design and ensuring the performance of these structures.

In this research, the adhesion of sandwich structures made of composite and geopolymer substrates is evaluated. Specimens are bonded either with an epoxy adhesive or a polyurethane adhesive. The surfaces treatment and roughness were evaluated for the improvement of the adhesion quality. Pull off tests were carried out to evaluate the influence of 
the surface treatment and adhesive type in the bonding performance of the sandwich structures.

\section{Materials and Methods}

The materials and manufacturing process of pull off sandwich specimens and single are described in this section.

\subsection{Composite material}

The composite material was manufactured by Pultrusão do Brasil using pultrusion process with an acrylic resin matrix and reinforced with unidirectional glass fibers. A surface veil and a superficial mat were applied for finishing. Composite plates with $3 \mathrm{~mm}$ thickness were produced. Finally, round plates of $20 \mathrm{~mm}$ diameter were cut in accordance with the dolly geometry, as shown in Figure 1.

\subsection{Geopolymer}

The geopolymer material applied is this study is a commercial geopolymer cement GP 109R1-M15 (Geo-Pol,
Brazil), indicated for applications of moderate mechanical performance. The main components are $\mathrm{SiO}_{2}, \mathrm{Al}_{2} \mathrm{O}_{3}, \mathrm{CaO}$, $\mathrm{Na}_{2} \mathrm{O}, \mathrm{K}_{2} \mathrm{O}$ and the secondary ones: $\mathrm{MgO}, \mathrm{TiO}_{2}, \mathrm{Fe}_{2} \mathrm{O}_{3}$ with the molar ratio of $\mathrm{SiO}_{2} / \mathrm{Al}_{2} \mathrm{O}_{3}$ equals 5.35 and the molar ratio of $\mathrm{M}_{2} \mathrm{O} / \mathrm{SiO}_{2}$ equals 0.21 . The thermal conductivity remains between $0.24-0.3 \mathrm{~W} / \mathrm{m} . \mathrm{K}^{25}$. Two geopolymer samples were prepared according with the manufacturer by using a proportion of 1:1 (in weight) of precursor and activator with between $5 \%$ and $10 \%$ weight of distilled water. A mixer was used to complete homogenization for 5 minutes under $100 \mathrm{rpm}$. Agglomerates were not added to the material. The geopolymers samples were cured in a silicone mold of $200 \times 10 \mathrm{~mm}$ for 30 days, as shown in Figure 2. The manufacturing operations were performed in the laboratory at room conditions.

\subsection{Pull off sandwich specimens}

A surface treatment was manually applied on the surfaces of the substrates using sandpaper (grit 80): unidirectional abrasion (UA) in parallel with the glass fibers, or bidirectional

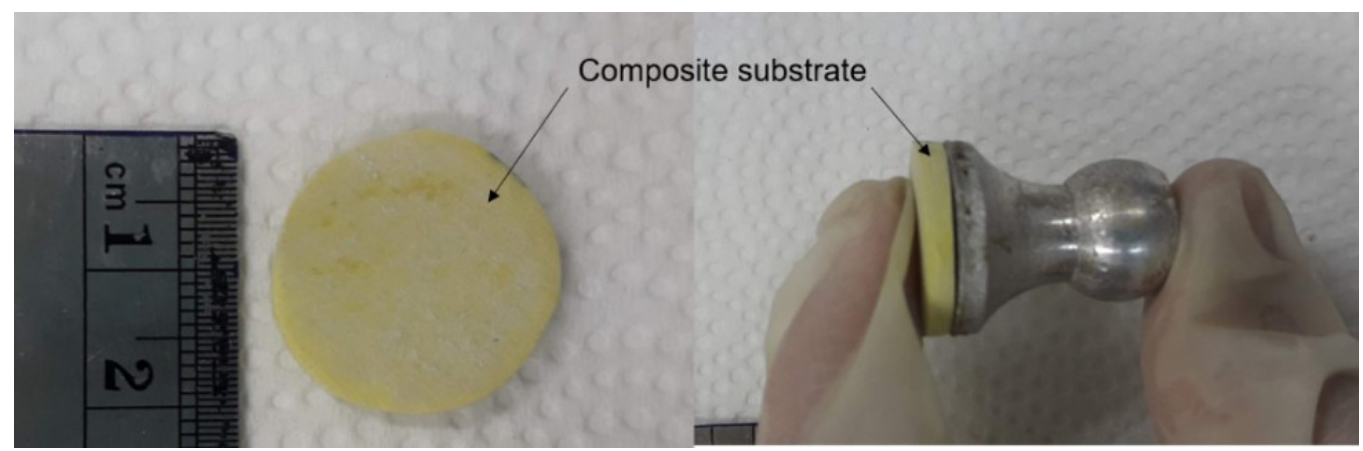

Figure 1. Composite samples for pull off tests.

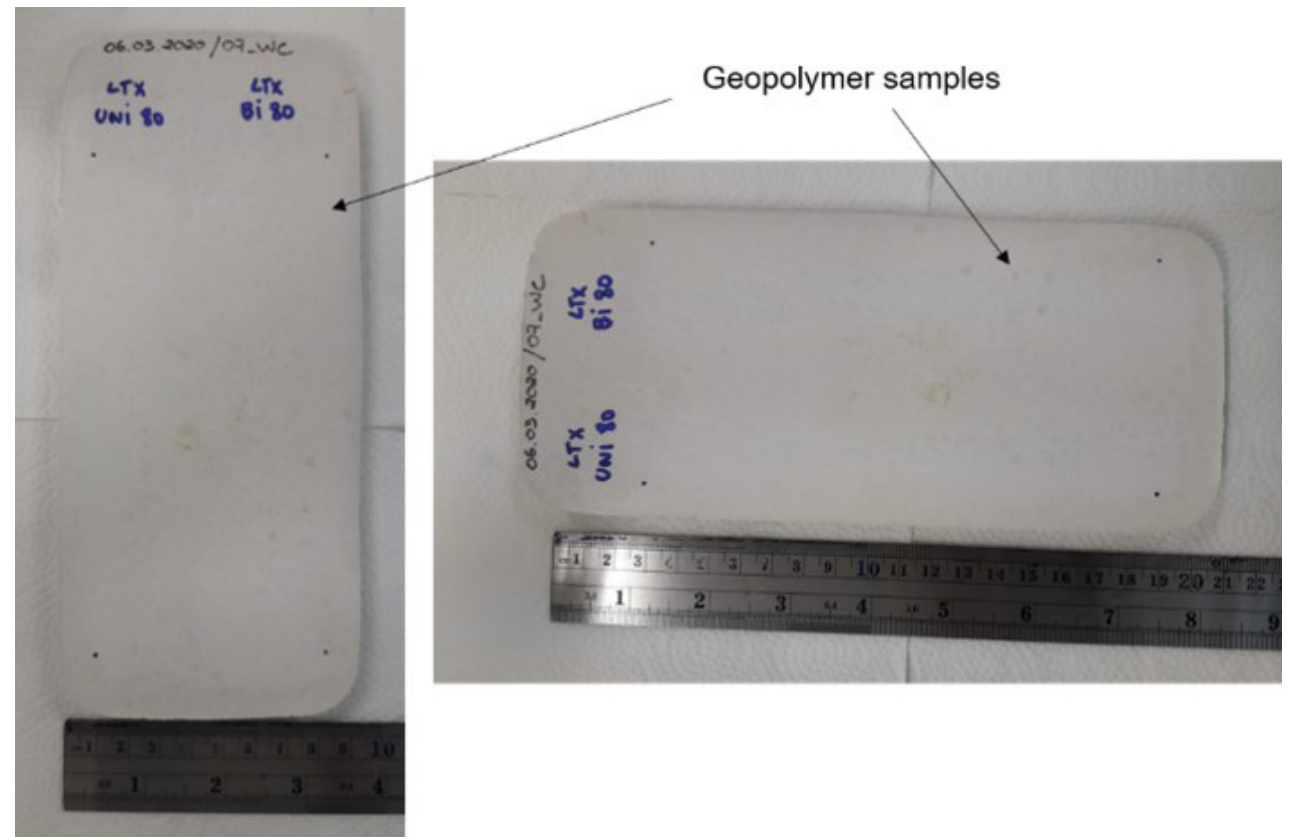

Figure 2. Geopolymer samples for pull off tests. 
abrasion (BA) with an additional abrasion in the perpendicular direction. After the surface treatment and prior to bonding, the substrates were cleaned with acetone in order to remove any grease or release agent remained from the previous processes. Two different adhesives, provided by Masterpol, were tested for bonding the composite and geopolymer materials: an epoxy adhesive (P 110) or a polyurethane adhesive (E LTX). The bonding process of the composite on the geopolymer and the dolly on the composite were performed in sequence. Figure 3 a shows a scheme of the pull off test specimen and Figure $3 \mathrm{~b}$ shows an image of the real specimen before testing.

\subsection{Mechanical tests}

The performance of the sandwich structures was evaluated using pull off tests, according with the standard ASTM D 454126. An automatic adhesion tester (Positest AT-A, Brazil) was applied, and five samples were tested for each configuration, as shows in Table 1. The parameters of adhesive material and surface treatment were analyzed.

\section{Results and Discussion}

This section presents the adhesive properties of the adhesives, as well as the roughness resulted from the surface treatment of the sandwich specimens. Then, the influence of the different adhesives and surface treatments in the performance of the sandwich structure is evaluated using peel off tests.

Table 1. Test matrix.

\begin{tabular}{clc}
\hline Adhesive & \multicolumn{1}{c}{ Surface treatment } & Number of tests \\
\hline \multirow{2}{*}{ Epoxy } & Unidirectional abrasion (UA) & 5 \\
\cline { 2 - 3 } & Bidirectional abrasion (BA) & 5 \\
\hline \multirow{2}{*}{ Polyurethane } & Unidirectional abrasion (UA) & 5 \\
\cline { 2 - 3 } & Bidirectional abrasion (BA) & 5 \\
\hline
\end{tabular}

\subsection{Adhesive properties}

Mechanical properties of the adhesives were evaluated using tensile tests in bulk specimens. Tests were performed in an Instron test machine model 5966 with a $10 \mathrm{kN}$ load cell at a constant displacement of $1 \mathrm{~mm} / \mathrm{min}$, according to the standard ASTM D $638^{27}$. Table 2 shows the average properties obtained from five tests and representative load-extension curves are presented in Figure 4. Both materials presented high strength and the maximum stresses of 17.17 $\mathrm{MPa}$ and $11.73 \mathrm{MPa}$ for the epoxy and polyurethane adhesives, respectively. However, the tested adhesives exhibited remarkably different mechanical behavior. The epoxy adhesive presented fragile behavior (Figure 4a) while the polyurethane adhesive a more ductile behavior (Figure 4b).

\subsection{Surface roughness}

In order to evaluate the effectiveness of the applied surface treatment, the surface roughness of the substrates was evaluated using a 3D rugosimeter (Talyscan 150, Taylor Hobson Precision). An area of 2 x $2 \mathrm{~mm}$ was analyzed with a spacing of $1 \mu \mathrm{m}$ (x-axis) and $10 \mu \mathrm{m}$ (y-axis). Three analyzes were performed for each of the three surface conditions: untreated, treated with unidirectional abrasion (UA) and treated with bidirectional abrasion (BA). The Table 3 shows the average surface roughness $(\mathrm{Ra})$ of the substrates in the three different conditions. The parameter Ra describes the average roughness of the profile, it means, the average between peaks and valleys. Results show that the surface treatment produced a significant increase of the surface roughness in

Table 2. Adhesive properties.

\begin{tabular}{ccc}
\hline Adhesive & Maximum Force $(\mathrm{N})$ & Maximum Stress $(\mathrm{MPa})$ \\
\hline Epoxy & $636.1 \pm 95.62$ & $17.17 \pm 2.58$ \\
\hline Polyurethane & $434.5 \pm 37.49$ & $11.73 \pm 1.01$ \\
\hline
\end{tabular}

a)

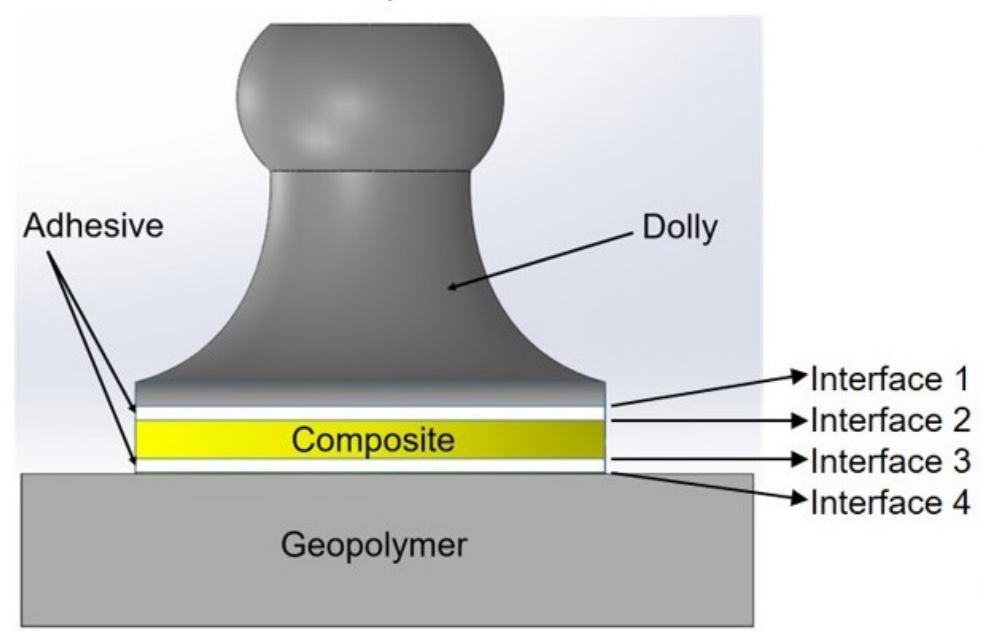

b)

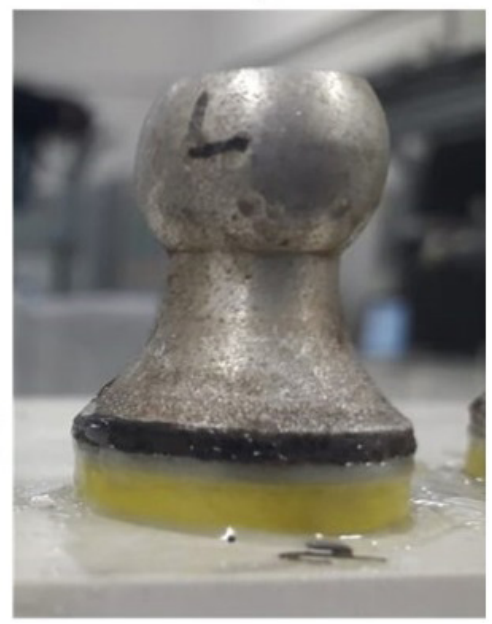

Figure 3. Pull off specimen (a) scheme and (b) real image. 
both geopolymer and composite samples. Higher roughness values were obtained from composite samples.

The 3D surface profiles of composite samples are presented in Figure 5. In Figure 5a, the untreated composite surface showed a more irregular aspect. A more regular surface profile is observed in composites treated with UA, in Figure 5b, and similarly in Figure 5c for the composites treated with BA. However, high peaks and valleys were present in all cases. The 3D surface profiles of geopolymer samples are shown in

Table 3. Surface roughness of the substrates.

\begin{tabular}{ccc}
\hline Substrate & Surface Treatment & $\mathrm{Ra}(\mu \mathrm{m})$ \\
\hline \multirow{3}{*}{$\begin{array}{c}\text { Pultruded } \\
\text { Composite }\end{array}$} & $\begin{array}{c}\text { Untreated } \\
\text { Unidirectional } \\
\text { abrasion (UA) }\end{array}$ & $0.961 \pm 0.140$ \\
\cline { 2 - 3 } & $\begin{array}{c}\text { Bidirectional } \\
\text { abrasion (BA) }\end{array}$ & $4.033 \pm 0.253$ \\
\hline \multirow{2}{*}{ Geopolymer } & $\begin{array}{c}\text { Untreated } \\
\text { Unidirectional } \\
\text { abrasion (UA) }\end{array}$ & $0.238 \pm 0.004$ \\
\cline { 2 - 3 } & $\begin{array}{c}\text { Bidirectional } \\
\text { abrasion (BA) }\end{array}$ & $2.930 \pm 0.461$ \\
\hline
\end{tabular}

a)

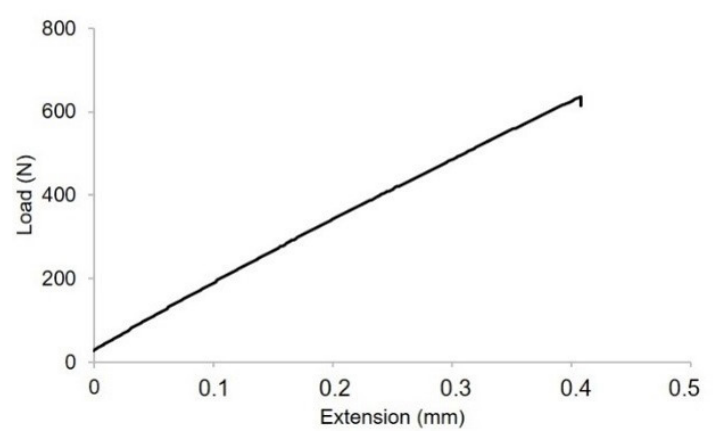

Figure 6. The untreated geopolymer surface presented more irregular profile, as shown in Figure 6a. The treatments of UA and BA (Figures $6 \mathrm{~b}$ and $6 \mathrm{c}$, respectively) resulted in a more homogeneous surface of the geopolymer. Overall, the mechanical surface treatments produced rougher and more homogeneous surfaces in both composite and geopolymer surfaces.

\subsection{Pull off tests}

Pull off tests were performed in composite-geopolymer sandwich specimens. The failure stresses and failure modes are shown in Table 4. The average failure stresses obtained from the experiments, according to the selected parameters of adhesive type and surface treatment, are shown in Figure 7. One result of each series was discarded due to damage in the specimen. For UA, the average failure stress was $5.88 \pm 0.25 \mathrm{MPa}$ while samples treated with BA presented an average pull off strength of $7.22 \pm 1.01 \mathrm{MPa}$. Regarding the specimens bonded with the polyurethane adhesive, the average strength obtained with UA and BA were $2.31 \pm 0.47 \mathrm{MPa}$ and 3.02 $\pm 0.32 \mathrm{MPa}$, respectively. Overall, samples bonded with the epoxy adhesive withstood higher loadings, which varied in according with the surface treatment. Specimens treated with BA presented higher strength than specimens treated with UA.

Figure 4. Representative load-extension curves of the (a) epoxy and (b) polyurethane adhesive.

a)

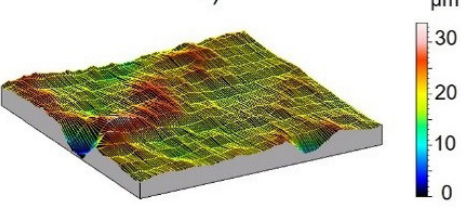

b)

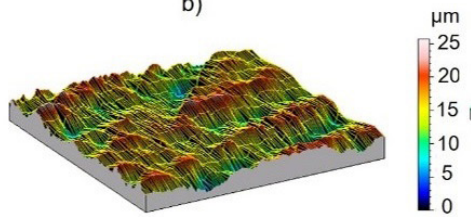

b)

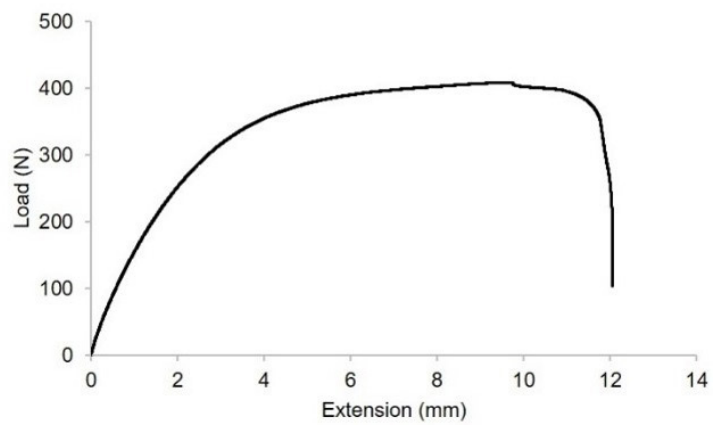

Figure 5. 3D surface profiles of composite samples: (a) untreated. (b) treated with UA and (c) treated with BA.

a)

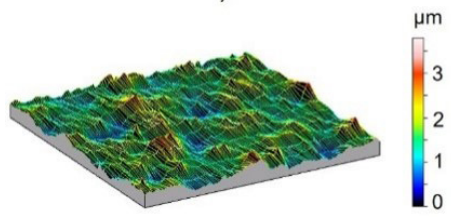

b)

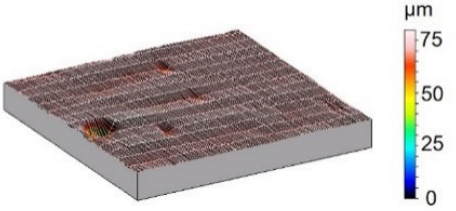

c)

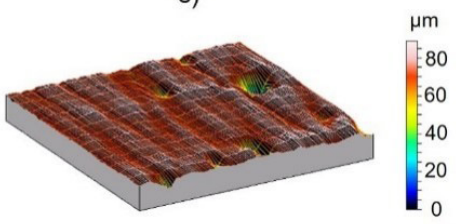

Figure 6. 3D surface profiles of geopolymer samples: (a) untreated. (b) treated with UA and (c) treated with BA. 
Table 4. Average strength of the pull off tests.

\begin{tabular}{|c|c|c|c|c|}
\hline Test & Adhesive & Surface Treatment & Failure Stress $(\mathrm{MPa})$ & Failure Mode \\
\hline 01 & \multirow[t]{10}{*}{ Epoxy } & \multirow[t]{5}{*}{ Unidirectional abrasion (UA) } & 5.61 & Substrate (geopolymer) + adhesive (interface 4) \\
\hline 02 & & & 5.73 & Adhesive (interface 4) \\
\hline 03 & & & & discarded \\
\hline 04 & & & 6.07 & Substrate (geopolymer) \\
\hline 05 & & & 6.11 & Substrate (geopolymer) + adhesive (interface 4) \\
\hline 06 & & \multirow[t]{5}{*}{ Bidirectional abrasion (BA) } & 6.55 & Substrate (geopolymer) \\
\hline 07 & & & 8.42 & Substrate (geopolymer) \\
\hline 08 & & & & discarded \\
\hline 09 & & & 7.69 & Substrate (geopolymer) \\
\hline 10 & & & 6.23 & Substrate (geopolymer) \\
\hline 11 & \multirow[t]{10}{*}{ Polyurethane } & \multirow[t]{5}{*}{ Unidirectional abrasion (UA) } & 2.05 & Substrate (geopolymer) \\
\hline 12 & & & 2.20 & Substrate (geopolymer) \\
\hline 13 & & & 2.99 & Substrate (geopolymer) \\
\hline 14 & & & & discarded \\
\hline 15 & & & 1.98 & Substrate (geopolymer) \\
\hline 16 & & \multirow[t]{5}{*}{ Bidirectional abrasion (BA) } & 2.96 & Substrate (geopolymer) \\
\hline 17 & & & 3.38 & Substrate (geopolymer) \\
\hline 18 & & & 3.14 & Substrate (geopolymer) \\
\hline 19 & & & 2.61 & Substrate (geopolymer) \\
\hline 20 & & & & discarded \\
\hline
\end{tabular}

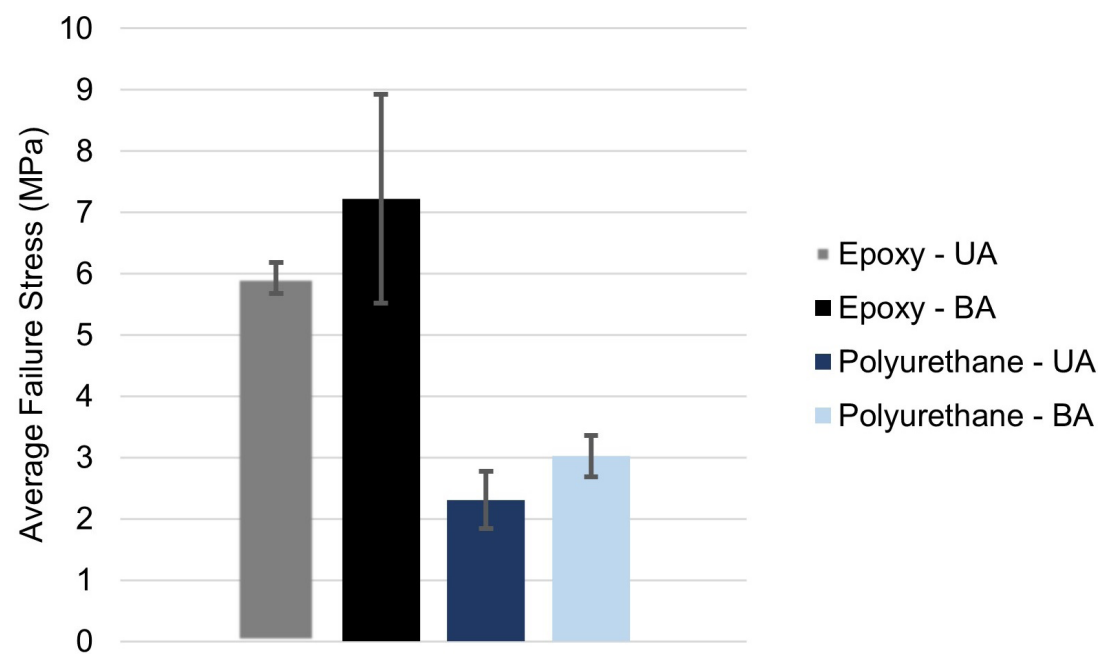

Figure 7. Average failure stress according to the parameters of adhesive type and surface treatment.

Representative Images of the fracture surfaces are shown in Figure 8. The predominant failure modes were either a combination of substrate and adhesive failure (Figure 8a) or pure substrate failure (Figure $8 \mathrm{~b}$ ). Samples bonded with the epoxy adhesive and treated with UA presented as the predominant failure mode a combination of substrate failure in the geopolymer and adhesive failure at interface 4 (see Figure $3 \mathrm{a}$ ). The adhesive failure indicates poor adhesion between the epoxy adhesive and the geopolymer substrate. In the case of samples bonded with the epoxy adhesive and treated with BA, substrate failure in the geopolymer was predominant. The contribution of adhesive failure was less significant than in the specimens treated with UA, indicating that the higher roughness of the substrates improved the adhesion quality between the geopolymer and the epoxy adhesive.

Specimens bonded with the polyurethane adhesive presented substrate failure in the geopolymer as the dominant failure mode. However, the failure stresses were inferior to the results of the specimens bonded with epoxy adhesive. The difference in the failure stresses of the samples bonded with the epoxy adhesive and polyurethane adhesive indicates a lower strength of the geopolymer substrate used in specimens bonded with polyurethane adhesive. In this case, it was manufactured using more distilled water, or $10 \%$ in weight, during the mixture process. In comparison, the geopolymer used in the epoxy samples was manufactured using 5\% weight of distilled water. Since the curing conditions were 
a)

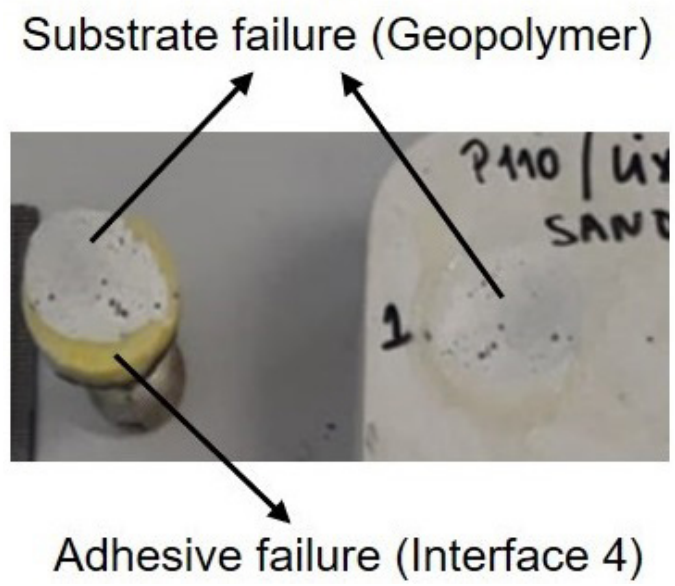

b)

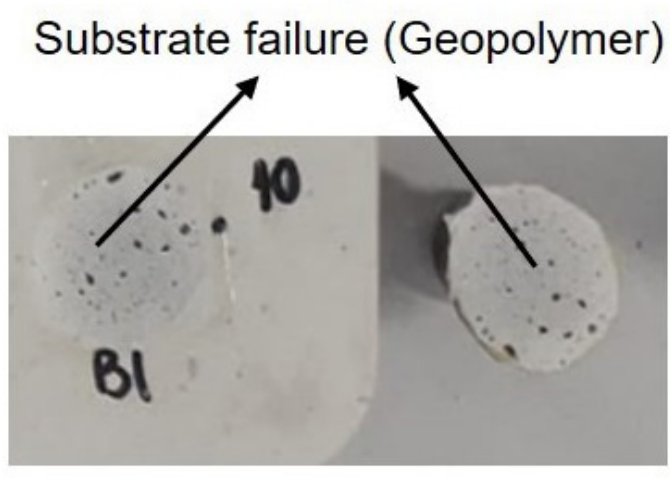

Figure 8. Fracture surfaces of specimens with (a) combined substrate and adhesive failure and (b) pure substrate failure.

a)

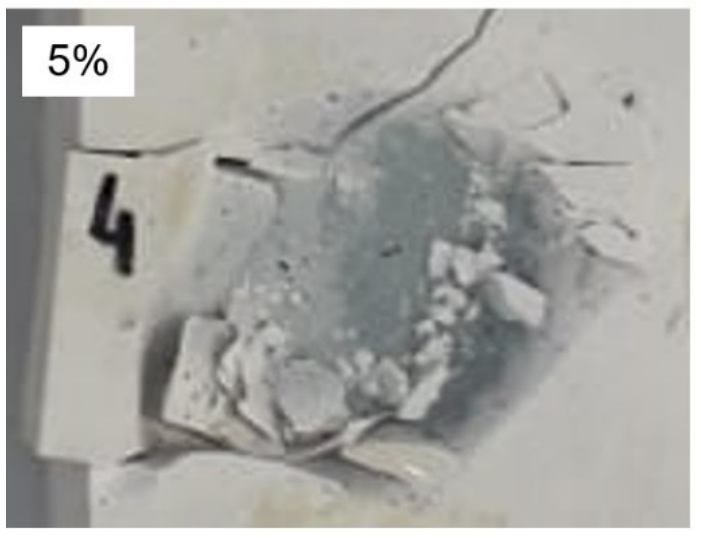

b)

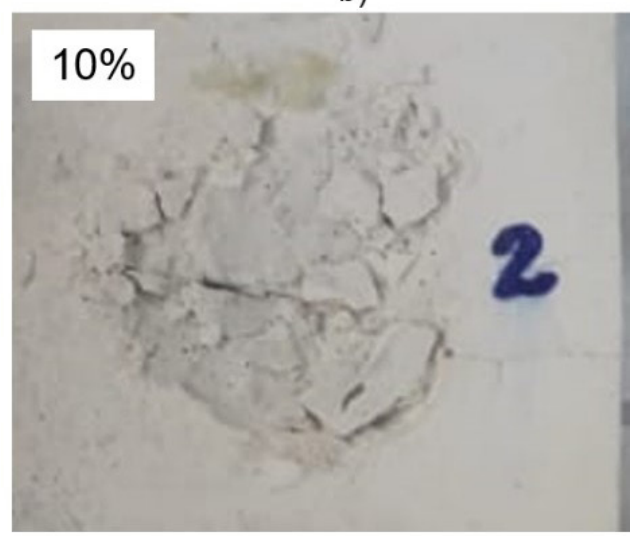

Figure 9. Detail of the fracture surface of a sample bonded with (a) epoxy and (b) polyurethane adhesive.

the same in all samples, it is concluded that the larger amount of water applied in the manufacturing process decreased the geopolymer strength. Figure 9 shows a comparison between the fracture surfaces with geopolymer failure in both cases. For a percentage of 5\% weight of water (Figure 9a), the fracture surface presented a more compacted aspect, while samples with $10 \%$ weight of water (Figure $9 \mathrm{~b}$ ) seem to have a less compacted fracture surface. Moreover, the efficacy of the surface preparation method in the polyurethane samples could not be evaluated, since the failure occurred predominantly in the substrate.

\section{Conclusions}

The adhesion of composite-geopolymer specimens was evaluated using epoxy and polyurethane adhesives. The bonded surfaces of the composite and the geopolymer substrates were treated by manual abrasion using two different procedures: unidirectional abrasion (UA) or bidirectional abrasion (BA). The strength of the sandwich structures was accessed using pull off tests.
Specimens treated with UA and bonded with epoxy adhesives presented either a combination of adhesive and substrate failure or pure substrate failure. The adhesive failure occurred in the geopolymer-adhesive interface. In the case of specimens treated with BA, the geopolymer substrate failure was dominant. This means that the increase in roughness provided by the BA resulted in better adhesion quality. Consequently, the strength of epoxy BA specimens were the highest.

Geopolymer failure was the predominant failure mode in the tests with polyurethane adhesive. These specimens presented small failure strength compared to the epoxy sample. This occurred because the geopolymer from the polyurethane samples were manufactured using a lower amount of water, $5 \%$ in weight, while the geopolymer from the epoxy samples had $10 \%$ weight of water.

\section{Acknowledgements}

This study is supported by the Coordenação de Aperfeiçoamento de Pessoal de Nível Superior - Brasil 
(CAPES), Conselho Nacional de Desenvolvimento Científico e Tecnológico (CNPq), Fundação Carlos Chagas Filho de Amparo à Pesquisa do Estado do Rio de Janeiro (FAPERJ) and Coordenação de Aperfeiçoamento de Pessoal de Nível Superior (CAPES).

\section{References}

1. Joshi SC. Manufacture techniques for polymer matrix composites. Cambridge: Woodhead Publishing Limited; 2012. p. 381-413.

2. Ding L, Liu X, Wang X, Huang H, Wu Z. Mechanical properties of pultruded basalt fiber-reinforced polymer tube under axial tension and compression. Constr Build Mater. 2018;176:629-37.

3. Zhao X, Wang X, Wu Z, Wu J. Experimental study on effect of resin matrix in basalt fiber reinforced polymer composites under static and fatigue loading. Constr Build Mater. 2020;242:118121.

4. Jawaiad M, Thariq M. Sustainable composites for aerospace applications. Cambridge: Woodhead Publishing; 2018. pp. 55-67.

5. Stazi F, Giampaoli M, Rossi M, Munafò P. Environmental ageing on GFRP pultruded joints: comparison between different adhesives. Compos Struct. 2015;133:404-14. http://dx.doi. org/10.1016/j.compstruct.2015.07.067.

6. Godat A, Légeron F, Gagné V, Marmion B. Use of FRP pultruded members for electricity transmission towers. Compos Struct. 2013;105:408-21.

7. Arouche MM, Budhe S, Alves LA, Teixeira de Freitas S, Banea $\mathrm{MD}$, de Barros S. Effect of moisture on the adhesion of CFRPto-steel bonded joints using peel tests. J Braz Soc Mech Sci Eng. 2018;40(1):10.

8. Arouche MM, Budhe S, Banea MD, Teixeira de Freitas S, de Barros S. Interlaminar adhesion assessment of carbon-epoxy laminates under salt water ageing using peel tests. Proc I Mech E Part L. 2019;233(8):1555-63.

9. Morgado T, Correia JR, Silvestre N, Branco FA. Experimental study on the fire resistance of GRRP pultruded tubular beams. Compos, Part B Eng. 2018:106-16. http://dx.doi.org/10.1016/j. compositesb.2017.11.036.

10. Aziz IH, Mustafa M, Abdullah AB, Yong HC, Ming LY, Hussin $\mathrm{K}$, et al. Manufacturing parameters influencing fire resistance of geopolymers: a review. JMDA. 2017;233(4):721-33. http:// dx.doi.org/10.1177/1464420716668203.

11. Luhar S, Sandeep C, Luhar I. Development of rubberized geopolymer concrete: strength and durability studies. Constr Build Mater. 2019;24:740-53. http://dx.doi.org/10.1016/j. conbuildmat.2019.01.185.

12. Deshmukh K, Parsai R, Anshul A, Singh A, Bharadwaj P, Gupta R, et al. Studies on fly ash based geopolymeric material for coating on mild steel by paint brush technique. Int $\mathrm{J}$ Adhes Adhes. 2017;75:139-44. http://dx.doi.org/10.1016/j. ijadhadh.2017.03.002.
13. Rego SR, Gomes KC, Rosas M, Torres SM, de Barros S. Application of geopolymeric adhesives in ceramic systems subjected to cyclic temperature environments. J Adhes. 2014;90(1):120-33.

14. De Barros S, De Souza JR, Gomes KC, Sampaio EM, Barbosa NP, Torres SM. Adhesion of geopolymer bonded joints considering surface treatments. J Adhes. 2012;88(4-6):4-6, 364-75.

15. Lahoti M, Tan KH, Yang E-H. A critical review of geopolymer properties for structural fire-resistance applications. Constr Build Mater. 2019;221:514-26.

16. Keller T, Tirelli T. Fadigue behavior pf adhesively connected pultruded GFRP profiles. Compos Struct. 2004;65(1):55-64. http://dx.doi.org/10.1016/j.compstruct.2003.10.008.

17. Ungureanu D, Țăranu N, Isopescu D-N, Lupăşteanu V, Scutaru M-C, Hudișteanu I. Failure particularities of adhesively bonded joints between pultruded GFRP composite profiles. IOP Conf Ser Mater Sci and Eng. 2018;400(3):032011.

18. Budhe S, Banea MD, de Barros S, da Silva LFM. An updated review of adhesively bonded joints in composite materials. Int J Adhes Adhes. 2017:30-42. http://dx.doi.org/10.1016/j. ijadhadh.2016.10.010.

19. Passos AC, Arouche MM, Aguiar RAA, Costa HRM, de Barros S, Sampaio EM. Adhesion of epoxy and polyurethane adhesives in pultruded composite material. J Adv Joining Processes. 2021;3:100045. http://dx.doi.org/10.1016/j.jajp.2021.100045.

20. Ghumatkar A, Budhe S, Sekhar R, Banea MD, de Barros S. Influence of adherend surface roughness on the adhesive bond strength. Lat Am J Solids Struct. 2016;13:2356-70. http:// dx.doi.org/10.1590/1679-78253066.

21. Guzanová A, Brezinová J, Draganovská D, Jaš F. A study of the effect of surface pre-treatment on the adhesion of coatings. J Adhes Sci Technol. 2014;28(17):1754-71.

22. Sousa JM, Correia JR, Firmo JP, Cabral-Fonseca S, Gonilha J. Effects of thermal cycles on adhesively bonded joints between pultruded GFRP adherends. Compos Struct. 2018:518-29. http:// dx.doi.org/10.1016/j.compstruct.2018.02.081.

23. Hamdi M, Saleh MN, Poulis JA. Improving the adhesion strength of polymers: effect of surface treatments. J Adhes Sci Technol. 2020;34(17):1853-70.

24. Arouche MM, Teixeira de Freitas S, de Barros S. On the influence of glass fiber mat on the mixed-mode fracture of compositeto-metal bonded joints. Compos Struct. 2021;256:113109.

25. Geo-Pol. Cimento Geopolimérico. Cimento GP propriedades [Internet]. 2018 [cited 2018 July 10]. Available from: http:// www.geopol.com.br/default.asp?area $=08 \&$ pag $=3 \&$ pro $=1$

26. ASTM International. ASTM D 4541-17. Standard Test Method for Pull-Off Strength of Coatings Using Portable Adhesion Testers. Conshohocken, PA: ASTM International; 2017.

27. ASTM International. ASTM D 638. Standard Test Method for Tensile Properties of Plastics. West Conshohocken, PA: ASTM International; 2014. 